\title{
Measuring the Level of Participation and Autonomy among people with Type II diabetes, Rafsanjan, Iran (2016)
}

\author{
Vazirinejad R, $\mathrm{PhD}^{1}$, Rezaeian M, $\mathrm{PhD}^{2}$, Nazari F, Medical Student ${ }^{3}$, Hosseini SM, MSc ${ }^{4^{*}}$ \\ 1- Professor, Dept. of Social Medicine, Social Determinants of Health Research Center, Rafsanjan University of Medical \\ Sciences, Rafsanjan, Iran. 2- Professor, Dept. of Epidemiology and Biostatistics, Occupational Environmental Research \\ Center, Medical School, Rafsanjan University of Medical Sciences, Rafsanjan, Iran. 3- Medical Student, Rafsanjan \\ University of Medical Sciences, Rafsanjan, Iran. 4- MSc in Epidemiology, Social Determinants of Health Research Center \\ Rafsanjan University of Medical Sciences, Rafsanjan, Iran.
}

\begin{abstract}
Received: December 2016, Accepted: January 2017

Background: A disease impacts patients' participation level in their individual and social life through impacting their physical and mental performance. Due to the increasing prevalence of diabetes mellitus (DM), and the importance of patients' participation and quality of life (QOL) and the determination of the most important aspects affected by the disease in the participation and Quality of Life of patients with type II DM in Rafsanjan, Iran, the present study was conducted.

Materials and Methods: In this cross-sectional study, 227 patients with type II DM were assessed. The data collection tool consisted of a 2-part questionnaire. The first part was a demographic characteristics checklist. The second part was the Persian version of the Impact on Participation and Autonomy (IPA-p) scale. The IPA-p scale was used to collect data on the subjects' participation in their own life. Then, a trained individual completed the demographic checklist through interviews. Subsequently, the subjects were asked to complete the IPA-p scale.The collected data were analyzed in SPSS software. Statistical tests such as t-test and ANOVA were used to compare the obtained means.

Results: The highest level of participation was observed in the age group of 30-49 years, and participation was higher in men, single individuals, and individuals with a good economic status.

Conclusions: The results of the present study suggested the presence of a statistically significant relationship between the participation of patients with type II DM and individual, social, economic factors. Thus, this disease causes a reduction in their participation in different life aspects, and therefore, causes a reduction in QOL. With the consideration of the long-term course of the disease, taking measures to improve individuals' participation level seems necessary.
\end{abstract}

Keywords: Participation, Quality of Life, Type 2 Diabetes

\section{Introduction}

The first step in the improvement of health is the measurement of the existing level of health. One of the best recognized ways of health level measurement is the evaluation of the quality of life (QOL). This concept is usually accompanied with the concepts of disability and impairment and is used as a suitable indicator in the evaluation of health status, especially in individuals with chronic diseases (1-3). According to the World Health Organization Quality of Life (WHOQOL) Group, QOL is individuals' understanding of their circumstances regarding the prevailing value-based and cultural systems which are correlated with the life goals, expectations, criteria, interests, presupposition, and standards $(4,5)$. However, there is no consensus on the definition of QOL and many researchers believe that this concept is multidimensional. There a three important components (physical, mental, and social

\footnotetext{
* Corresponding author: Sayed Mortaza Hosseini, Social Determinants of Health Research Center Rafsanjan University of Medical Sciences, Rafsanjan, Iran.

E-mail: mhosseini622@gmail.com
} 
performance) in life which must be taken into consideration in the evaluation of QOL (6).

The term QOL has been frequently used during the past 25 years; however, its meaning is still unclear and its evaluation methods differ from one study to the next. In a study conducted in 1999, the researchers defined QOL as that which the patient expresses (7). A discussion on QOL is in fact a discussion on the good and bad issues in an individuals' life. The concept of QOL refers to the essence of an individual's life, and the ability to maintain or even improve the quality of living (8).

Nevertheless, one of the weaknesses of this indicator is that the concept of QOL is assessed subjectively, and this significantly decreases the accuracy of the results. As a result, that which has been measure as the level of QOL is impacted by the individual's emotions and will present different results for the same status under different circumstances. Thus, it seems that another indicator and concept which does not include negatively charged concepts such as impairment and which can evaluate the health status of individuals through a less subjectively and more tangible and objective manner is required. Therefore, the participation index has been introduced during the present decade. The concept of participation is defined as the individual's independence and autonomy in performing individual and social roles and responsibilities (9).

The WHO has defined participation as the degree of involvement of an individual in life issues with the consideration of health status, physical and structural performance, ability to perform tasks, and other underlying factors (10). The concept of participation also encompasses different aspects of the life of the individual and can affect these aspects in accordance with the health status of the individual. For example, limitation in physical movement ability can impact the individual's autonomy, participation in activities such as recreational activities, and type of occupation (4).
On the other hand, one the main health issues of developed and developing societies in the present era is the high incidence and prevalence of diabetes mellitus (DM). Economic burden of disease is not the only important issue; the physical and mental burden of disease on patients and their families cannot be overlooked. Previous studies have shown that almost all aspects of the life of individuals can be affected by DM and result in reduced satisfaction, QOL, and participation in daily life $(11,12)$. DM is prevalent in both developing and developed countries. Due to extensive changes in lifestyle (increased urbanization and elderly population, decreased physical exercise, and variation in dietary patterns), the number of individuals with DM is increasing. According to the most recent report by the International Diabetes Federation (IDF), more than 382 million individuals had DM in 2014, and this number has been predicted to reach 592 million individuals by 2035 (13). According to this report, currently, more than 4.5 million individuals have DM in Iran, and this number is expected to reach 8.4 million individuals by 2035 (13). Moreover, the prevalence of DM was estimated as $8.34 \%$ in Iran in 2014. The burden of DM and its complications due to increased number of patients and premature death is of great importance. In 2013, 1 individual died every 6 seconds due to DM and the cost of DM care and treatment has been estimated to be 584 milliard dollars (13). The long-term complications of DM include retinal damage and loss of sight, kidney damage and renal failure, peripheral nerve damage and risk of foot ulcers, amputation, and autonomic nerve damage which results in gastrointestinal, genitourinary, and cardiovascular symptoms, and sexual dysfunction. Increased rate of atherosclerosis and cardiovascular, peripheral arterial, and cerebrovascular disease incidence is observed in patients with DM. Increased blood pressure and lipoprotein metabolism disorders are frequently observed in patients with DM (14). Thus, numerous tools have been designed to measure the QOL of patients 
with DM and determine the main aspects affected by DM (15). The determination of these aspects provides the necessary data for planning for QOL improvement and the participation level of patients. In the present study, the effect of type II DM was evaluated on the level of participation of patients in different aspects of their life. The aim of the present study was to determine the main aspects affected by type II DM in patients' lives in Rafsanjan, Iran, in 2016.

\section{Material and Methods}

This descriptive study was conducted during the first 6 months of 2016. First, all patients with type II DM who had a medical record at Ali-ibn Abi Talib Hospital in Rafsanjan were determined. Their disease had been approved by internal specialists and endocrinologists through clinical methods. The participants were randomly selected and asked to participate in the study. From among the 4000 patients with type II DM in this clinic, 300 individuals were selected based on the sample volume equation (Equation 1).

$\mathrm{n}=(\mathrm{zs} / \mathrm{d})^{2} \quad$ (Equation 1)

Of those invited to take part in the study, 37 individuals were not willing to participate in the study; therefore, the study was conducted on 227 patients.

The data collection tool consisted of a 2-part questionnaire. The first part was a demographic characteristics checklist including age, gender, socioeconomic status [based on monthly income (poor: below 700 thousand toman, average: between 700 thousand toman and 2 million toman, good:above 2 million toman)], marital status, education, and duration of illness. The second part was the Persian version of the Impact on Participation and Autonomy (IPA-p) scale. The IPA-p scale was used to collect data on the subjects' participation in their own life. The questionnaire is scores based on a 5-point Likert scale (very well, good, average, poor, and very poor). It should be noted that the study method and goals were explained to all subjects and they were asked to complete the questionnaire if they wished.

The IPA-p scale was first designed by Cardol et al. in Dutch. It is one of the most important questionnaires used to evaluate the degree of participation in life among individuals with chronic diseases. Its reliability and validity have been repeatedly approved by researchers $(19,16)$. It should be noted that the reliability and validity of the IPA-p scale have been approved for Persian speakers with multiple sclerosis (MS) by Vazirinejad et al. (17). They obtained a Spearman's correlation coefficient of higher than 0.8 and a Cronbach's alpha of 0.86-0.91 (17).

This questionnaire consists of 10 subscales. The first subscale is related to mobility and contains 10 questions regarding the individual's level of mobility (with or without the help of others or use of devices). The second subscale is related to self-care (personal care) and consists of 6 questions. The third subscale is related to household tasks and family roles, contains 7 questions, and assesses the impact of the health status and inability of the patient on performing these tasks and roles. The forth subscale consists of 2 questions on spending money. The fifth subscale comprises 2 questions on leisure. The sixth subscale is related to social relations and consists of 8 questions. The seventh subscale contains 6 questions on paid and voluntary work. The eighth subscale is related to education and learning and contained 2 questions. The 2 questions in the ninth subscale, related to assistance and support of others, assess the patient's opportunities to assist and support other family members, neighbors, or friends. The tenth subscale contains 5 questions regarding playing a role in religious affairs. The final question reached a general conclusion regarding the previous questions of the IPA-p scale.

The subjects received sufficient information on the method and goals of the study. Then, a trained individual completed the demographic checklist through interviews in a quite environment (the clinic). Subsequently, the 
subjects were asked to complete the IPA-p scale.

Scoring was performed based on the instructions of the tool itself. The collected data were analyzed in SPSS software (version 22, IBM Corporation, Armonk, NY, USA). Statistical tests such as t-test and ANOVA were used to compare the obtained means.

\section{Results}

The subjects of the present study consisted of 227 individuals; 115 (50.7\%) women and 112 (49.3\%) men. The participants' age ranged between 31 and 90 years with a mean of 54.06 \pm 12.20 years. In terms of marital status, 222 (97.8\%) individuals were married and the remaining subjects were single.

The results showed that, based on the IPA-p scale, the participation score of $53.7 \%$ of subjects in the dimension of mobility was higher than the average score. Moreover, the score of $30.8 \%, 50.2 \%, 30 \%, 56.8 \%, 29.1 \%$, $91.6 \%, 76.2 \%, 76.2 \%$, and $51.1 \%, 26 \%$ of the subjects in the dimensions of self-care, household tasks and family roles, spending money, leisure, social relations, paid and voluntary work, education and learning, assistance and support of others, and playing a role in religious affairs, respectively, were higher than the average score. The results suggested a statistically significant relationship between age and degree of participation in all dimensions $(\mathrm{P}<0.001)$. The highest participation score was related to the age group of 30-49 years (Table1).

Table 1: Frequency distribution of the participation score of patients with type II diabetes mellitus based on age in 2016

\begin{tabular}{|c|c|c|c|c|}
\hline \multirow{2}{*}{$\begin{array}{c}\text { IPA-p subscales } \\
\text { (maximum score: } 5 \text { ) }\end{array}$} & \multicolumn{3}{|c|}{ Mean \pm SD (Based on age) } & \multirow{2}{*}{ ANOVA results } \\
\hline & $30-49$ years & $50-69$ years & $>70$ years & \\
\hline Mobility & $3 / 65 \pm 0 / 50$ & $3 / 16 \pm 0 / 49$ & $2 / 81 \pm 0 / 69$ & $\mathrm{~F}=30 / 659, \mathrm{P}<0 / 001$ \\
\hline Self-care & $3 / 90 \pm 0 / 43$ & $3 / 54 \pm 0 / 27$ & $3 / 18 \pm 0 / 60$ & $\mathrm{~F}=40 / 400, \mathrm{P}<0 / 001$ \\
\hline Household tasks and family roles & $3 / 66 \pm 0 / 52$ & $3 / 17 \pm 0 / 43$ & $2 / 82 \pm 0 / 61$ & $\mathrm{~F}=36 / 062, \mathrm{P}<0 / 001$ \\
\hline Spending money & $3 / 35 \pm 0 / 49$ & $3 / 05 \pm 0 / 41$ & $2 / 60 \pm 0 / 47$ & $\mathrm{~F}=28 / 038, \mathrm{P}<0 / 001$ \\
\hline Leisure & $3 / 15 \pm 0 / 56$ & $2 / 71 \pm 0 / 46$ & $2 / 56 \pm 0 / 62$ & $\mathrm{~F}=20 / 283, \mathrm{P}<0 / 001$ \\
\hline Social relations & $4 / 05 \pm 0 / 46$ & $3 / 83 \pm 0 / 28$ & $3 / 54 \pm 0 / 46$ & $\mathrm{~F}=19 / 380, \mathrm{P}<0 / 001$ \\
\hline Paid and voluntary work & $3 / 11 \pm 0 / 92$ & $2 / 72 \pm 1 / 01$ & $2 / 00 \pm 1 / 22$ & $\mathrm{~F}=2 / 018, \mathrm{P}=0 / 144$ \\
\hline Education and learning & $1 / 49 \pm 0 / 57$ & $1 / 52 \pm 0 / 55$ & $1 / 26 \pm / 36$ & $\mathrm{~F}=1 / 609, \mathrm{P}=0 / 203$ \\
\hline Assistance and support of others & $3 / 11 \pm 0 / 51$ & $2 / 67 \pm 0 / 46$ & $2 / 48 \pm 0 / 70$ & $\mathrm{~F}=21 / 757, \mathrm{P}<0 / 001$ \\
\hline Playing a role in religious affairs & $4 / 28 \pm 0 / 43$ & $4 / 12 \pm 0 / 30$ & $4 / 06 \pm 0 / 61$ & $\mathrm{~F}=4 / 722, \mathrm{P}=0 / 010$ \\
\hline
\end{tabular}

IPA-p: The Persian version of the Impact on Participation and Autonomy

Furthermore, excluding the dimensions of spending money $(\mathrm{P}=0.012)$, social relations $(\mathrm{P}=0.020)$, and paid and voluntary work $(\mathrm{P}<$ 0.001 ), no difference was observed between mean scores in terms of gender in any of the dimensions. The degree of participation of men was higher in the three dimensions of spending money, social relations, and paid and voluntary work (Table 2). Based on the results presented in table 2, there was statistically significant relationship between participation and history of illness. Except the dimensions of spending money $(\mathrm{P}=0.020)$ and social relations $(\mathrm{P}=0.017)$, no significant Difference was observed between single and married individuals in any of the dimensions. In the two abovementioned dimensions, the participation of single individuals was higher than married individuals (Table 3 ). 
Table 2: Frequency distribution of the participation score of patients with type II diabetes mellitus based on gender and history of illness in 2016

\begin{tabular}{|c|c|c|c|c|c|c|}
\hline \multirow{2}{*}{$\begin{array}{l}\text { IPA-p subscales } \\
\text { (maximum score: 5) }\end{array}$} & \multicolumn{2}{|c|}{$\begin{array}{c}\text { Mean } \pm \text { SD (Based on } \\
\text { gender) }\end{array}$} & \multirow[t]{2}{*}{ T-test results } & \multicolumn{2}{|c|}{$\begin{array}{c}\text { Mean } \pm \text { SD (Based on } \\
\text { history of illness) }\end{array}$} & \multirow[t]{2}{*}{ T-test results } \\
\hline & Female & Male & & Yes & No & \\
\hline Mobility & $3 / 32 \pm 0 / 61$ & $3 / 22 \pm 0 / 55$ & $\mathrm{t}=1 / 312, \mathrm{p}=0 / 191$ & $3 / 3 . \pm 0 / 54$ & $3 / 27 \pm 0 / 49$ & $\mathrm{t}=0 / 386, \mathrm{p}=0 / 700$ \\
\hline Self-care & $3 / 59 \pm 0 / 49$ & $3 / 63 \pm 0 / 36$ & $\mathrm{t}=-0 / 681, \mathrm{p}=0 / 496$ & $3 / 61 \pm 0 / 47$ & $3 / 63 \pm 0 / 36$ & $\mathrm{t}=0 / 266, \mathrm{p}=0 / 791$ \\
\hline $\begin{array}{l}\text { Household tasks and } \\
\text { family roles }\end{array}$ & $3 / 32 \pm 0 / 61$ & $3 / 42 \pm 0 / 48$ & $\mathrm{t}=1 / 002, \mathrm{p}=0 / 318$ & $3 / 20 \pm 058$ & $3 / 27 \pm 0 / 49$ & $\mathrm{t}=0 / 308, \mathrm{p}=0 / 758$ \\
\hline Spending money & $3 / 01 \pm 0 / 50$ & $3 / 17 \pm 0 / 49$ & $\mathrm{t}=-2 / 534, \mathrm{p}=0 / 012$ & $3 / 13 \pm 0 / 51$ & $3 / 09 \pm 0 / 48$ & $\mathrm{t}=0 / 502, \mathrm{p}=0 / 616$ \\
\hline Leisure & $2 / 89 \pm 0 / 63$ & $2 / 77 \pm 0 / 47$ & $\mathrm{t}=1 / 574, \mathrm{p}=0 / 117$ & $2 / 88 \pm 0 / 62$ & $2 / 73 \pm 0 / 40$ & $\mathrm{t}=1 / 860, \mathrm{p}=0 / 123$ \\
\hline Social relations & $3 / 80 \pm 0 / 37$ & $3 / 92 \pm 0 / 40$ & $\mathrm{t}=-2 / 348, \mathrm{p}=0 / 020$ & $3 / 86 \pm 0 / 43$ & $3 / 91 \pm 0 / 39$ & $\mathrm{t}=-0 / 723, \mathrm{p}=0 / 471$ \\
\hline $\begin{array}{c}\text { Paid and voluntary } \\
\text { work }\end{array}$ & $2 / 09 \pm 1 / 15$ & $3 / 29 \pm 0 / 46$ & $t=-4 / 760, p<0 / 001$ & $2 / 67 \pm 1 / 07$ & $1 / 47 \pm 0 / 40$ & $\mathrm{t}=-0 / 096, p=0 / 924$ \\
\hline Education and learning & $1 / 43 \pm 0 / 61$ & $1 / 54 \pm 0 / 47$ & $t=-1 / 434, p=0 / 153$ & $1 / 50 \pm 0 / 60$ & $2 / 74 \pm 0 / 52$ & $\mathrm{t}=0 / 240, \mathrm{p}=0 / 811$ \\
\hline $\begin{array}{l}\text { Assistance and support } \\
\text { of others }\end{array}$ & $2 / 71 \pm 0 / 64$ & $2 / 85 \pm 0 / 44$ & $\mathrm{t}=-1 / 865, \mathrm{p}=0 / 064$ & $2 / 82 \pm 0 / 60$ & $2 / 74 \pm 0 / 5$ & $\mathrm{t}=0 / 753, \mathrm{p}=0 / 453$ \\
\hline $\begin{array}{l}\text { Playing a role in } \\
\text { religious affairs }\end{array}$ & $4 / 15 \pm 0 / 42$ & $4 / 17 \pm 0 / 36$ & $\mathrm{t}=-0 / 242, \mathrm{p}=0 / 809$ & $4 / 19 \pm 0 / 44$ & $50 / 35$ & $\mathrm{t}=0 / 662, \mathrm{p}=0 / 509$ \\
\hline
\end{tabular}

In addition, with the exception of the dimension of spending money $(\mathrm{P}=0.038)$, no significant relationship was observed between participation and severity of illness in the dimensions. In the dimension of spending money, the participation of patients with controlled DM was higher than those with uncontrolled DM (Table 3).

Table 3: Frequency distribution of the participation score of patients with type II diabetes mellitus based on marital status and severity of disease in 2016

\begin{tabular}{|c|c|c|c|c|c|c|}
\hline \multirow{2}{*}{$\begin{array}{l}\text { IPA-p subscales } \\
\text { (maximum score: } 5 \text { ) }\end{array}$} & \multicolumn{2}{|c|}{$\begin{array}{l}\text { Mean } \pm \text { SD (Based on } \\
\text { marital status) }\end{array}$} & \multirow{2}{*}{$\begin{array}{l}\text { T-test } \\
\text { results }\end{array}$} & \multicolumn{2}{|c|}{$\begin{array}{c}\text { Mean } \pm \text { SD (Based on severity of } \\
\text { disease) }\end{array}$} & \multirow{2}{*}{$\begin{array}{l}\text { T-test } \\
\text { results }\end{array}$} \\
\hline & Spingle & Married & & $\begin{array}{l}\text { Controlled } \\
\text { diabetes }\end{array}$ & $\begin{array}{c}\text { Uncontrolled } \\
\text { diabetes }\end{array}$ & \\
\hline Mobility & $3 / 28 \pm 1 / 30$ & $3 / 27 \pm 0 / 57$ & $\begin{array}{c}\mathrm{t}=0 / 21 \\
\mathrm{p}=0 / 984\end{array}$ & $3 / 28 \pm 0 / 57$ & $3 / 19 \pm 0 / 66$ & $\begin{array}{l}\mathrm{t}=0 / 836 \\
\mathrm{p}=0 / 404\end{array}$ \\
\hline Self-care & $3 / 50 \pm 1 / 46$ & $3 / 61 \pm 0 / 39$ & $\begin{array}{l}\mathrm{t}=-0 / 167 \\
\mathrm{p}=0 / 875\end{array}$ & $3 / 63 \pm 0 / 42$ & $3 / 51 \pm 0 / 46$ & $\begin{array}{l}\mathrm{t}=1 / 499 \\
\mathrm{p}=0 / 135\end{array}$ \\
\hline $\begin{array}{l}\text { Household tasks and } \\
\text { family roles }\end{array}$ & $3 / 31 \pm 1 / 40$ & $3 / 28 \pm 0 / 52$ & $\begin{array}{c}\mathrm{t}=0 / 55 \\
\mathrm{p}=0 / 959\end{array}$ & $3 / 30 \pm 0 / 53$ & $3 / 17 \pm 0 / 60$ & $\begin{array}{l}\mathrm{t}=1 / 309 \\
\mathrm{p}=0 / 192\end{array}$ \\
\hline Spending money & $3 / 60 \pm 0 / 65$ & $3 / 08 \pm 0 / 49$ & $\begin{array}{l}\mathrm{t}=2 / 338 \\
\mathrm{p}=0 / 020\end{array}$ & $3 / 13 \pm 0 / 45$ & $2 / 94 \pm 0 / 59$ & $\begin{array}{l}\mathrm{t}=2 / 086 \\
\mathrm{p}=0 / 038\end{array}$ \\
\hline Leisure & $3 / 10 \pm 1 / 24$ & $2 / 83 \pm 0 / 53$ & $\begin{array}{l}\mathrm{t}=0 / 489 \\
\mathrm{p}=0 / 650\end{array}$ & $2 / 86 \pm 0 / 52$ & $2 / 69 \pm 0 / 66$ & $\begin{array}{l}\mathrm{t}=1 / 708 \\
\mathrm{p}=0 / 089\end{array}$ \\
\hline Social relations & $4 / 27 \pm 0 / 56$ & $3 / 85 \pm 0 / 38$ & $\begin{array}{l}\mathrm{t}=2 / 397 \\
\mathrm{p}=0 / 017\end{array}$ & $3 / 88 \pm 0 / 38$ & $3 / 78 \pm 0 / 44$ & $\begin{array}{l}\mathrm{t}=1 / 363 \\
\mathrm{p}=0 / 174\end{array}$ \\
\hline $\begin{array}{l}\text { Paid and voluntary } \\
\text { work }\end{array}$ & & & & $2 / 87 \pm 0 / 99$ & $2 / 21 \pm 1 / 16$ & $\begin{array}{l}\mathrm{t}=1 / 584 \\
\mathrm{p}=0 / 120\end{array}$ \\
\hline Education and learning & $1 / 12 \pm 0 / 48$ & $1 / 49 \pm 0 / 54$ & $\begin{array}{l}\mathrm{t}=-1 / 346 \\
\mathrm{p}=0 / 180\end{array}$ & $1 / 50 \pm 0 / 57$ & $1 / 38 \pm 0 / 37$ & $\begin{array}{l}\mathrm{t}=1 / 196 \\
\mathrm{p}=0 / 233\end{array}$ \\
\hline $\begin{array}{c}\text { Assistance and support } \\
\text { of others }\end{array}$ & $2 / 90 \pm 1 / 14$ & $2 / 78 \pm 0 / 54$ & $\begin{array}{l}\mathrm{t}=0 / 236 \\
\mathrm{p}=0 / 825\end{array}$ & $2 / 81 \pm 0 / 53$ & $2 / 64 \pm 0 / 67$ & $\begin{array}{l}t=1 / 680 \\
p=0 / 094\end{array}$ \\
\hline $\begin{array}{l}\text { Playing a role in } \\
\text { religious affairs }\end{array}$ & $4 / 08 \pm 0 / 83$ & $4 / 16 \pm 0 / 38$ & $\begin{array}{l}\mathrm{t}=-0 / 222 \\
\mathrm{p}=0 / 835\end{array}$ & $4 / 17 \pm 0 / 42$ & $4 / 11 \pm 0 / 24$ & $\begin{array}{l}\mathrm{t}=1 / 164 \\
\mathrm{p}=0 / 248\end{array}$ \\
\hline
\end{tabular}

*The seventh subscale (paid and voluntary work) based on marital status was eliminated due to the high number of subjects who had not responded to this subscale. 
Table 4: Frequency distribution of the participation score of patients with type II diabetes mellitus based on economic status in 2016

\begin{tabular}{ccccc}
\hline \multirow{2}{*}{$\begin{array}{c}\text { IPA-p subscales } \\
\text { (maximum score: } 5)\end{array}$} & \multicolumn{2}{c}{ Mean \pm SD Based on economic status } & ANOVA results \\
\cline { 2 - 4 } & $3 / 18 \pm 0 / 54$ & $3 / 30 \pm 0 / 59$ & $3 / 11 \pm 0 / 61$ & $\mathrm{~F}=1 / 329, \mathrm{P}=0 / 267$ \\
\hline Mobility & $3 / 56 \pm 0 / 30$ & $3 / 63 \pm 0 / 46$ & $3 / 18 \pm 0 / 60$ & $\mathrm{~F}=2 / 237, \mathrm{P}=0 / 109$ \\
\hline Self-care & $3 / 13 \pm 0 / 44$ & $3 / 33 \pm 0 / 55$ & $3 / 11 \pm 0 / 63$ & $\mathrm{~F}=3 / 292, \mathrm{P}=0 / 039$ \\
\hline $\begin{array}{c}\text { Household tasks and } \\
\text { family roles }\end{array}$ & $3 / 15 \pm 0 / 44$ & $3 / 11 \pm 0 / 49$ & $2 / 70 \pm 0 / 53$ & $\mathrm{~F}=5 / 319, \mathrm{P}=0 / 006$ \\
\hline Spending money & $2 / 79 \pm 0 / 41$ & $2 / 85 \pm 0 / 58$ & $2 / 73 \pm 0 / 59$ & $\mathrm{~F}=0 / 410, \mathrm{P}=0 / 664$ \\
\hline Leisure & $3 / 85 \pm 0 / 37$ & $3 / 87 \pm 0 / 41$ & $3 / 71 \pm 0 / 12$ & $\mathrm{~F}=1 / 306, \mathrm{P}=0 / 273$ \\
\hline Social relations & $3 / 44 \pm 0 / 31$ & $2 / 53 \pm 1 / 08$ & $1 / 50 \pm 0 / 00$ & $\mathrm{~F}=5 / 718, \mathrm{P}=0 / 006$ \\
\hline $\begin{array}{c}\text { Paid and voluntary } \\
\text { work }\end{array}$ & $1 / 65 \pm 0 / 62$ & $1 / 45 \pm 0 / 52$ & $1 / 25 \pm 0 / 26$ & $\mathrm{~F}=3 / 224, \mathrm{P}=0 / 042$ \\
\hline $\begin{array}{c}\text { Education and } \\
\text { learning }\end{array}$ & $2 / 89 \pm 0 / 39$ & $2 / 77 \pm 0 / 59$ & $2 / 56 \pm 0 / 54$ & $\mathrm{~F}=2 / 061, \mathrm{P}=0 / 130$ \\
\hline $\begin{array}{c}\text { Assistance and } \\
\text { support of others }\end{array}$ & $4 / 17 \pm 0 / 38$ & $4 / 15 \pm 0 / 40$ & $4 / 16 \pm 0 / 39$ & $\mathrm{~F}=0 / 046, \mathrm{P}=0 / 955$ \\
\hline $\begin{array}{c}\text { Playing a role in } \\
\text { religious affairs }\end{array}$ & & &
\end{tabular}

No significant relationship was observed between participation and economic status in the dimensions, except the dimensions of household tasks and family roles $(\mathrm{P}=0.039)$, spending money and paid and voluntary works $(\mathrm{P}=0.006)$, and education and learning $(\mathrm{P}=$ 0.042). In these dimensions, the participation of subjects with a good economical status was higher (Table 4).

There was no significant Relationship between the participation score and occupational status of the subjects, except in the dimensions of spending money $(\mathrm{P}=0.012)$, social relations $(\mathrm{P}=0.049)$, paid and voluntary work $(\mathrm{P}<$ $0.001)$, and education and learning ( $\mathrm{P}<$ 0.001). The highest level of participation in the dimensions of spending money, social relations, paid and voluntary work, and education and learning was, respectively, related to self-employed, unemployed, employed, and employed individuals (Table $5)$.

Table 5: Frequency distribution of the participation score of patients with type II diabetes mellitus based on occupational status in 2016

\begin{tabular}{cccccc}
\hline \multirow{2}{*}{$\begin{array}{c}\text { IPA-p subscales } \\
\text { (maximum score: 5) }\end{array}$} & \multicolumn{4}{c}{ Mean \pm SD Based on economic status } & ANOVA results \\
\cline { 2 - 5 } & Unemployed & Homemaker & Employed & $\begin{array}{c}\text { Self- } \\
\text { employed }\end{array}$ & \\
\hline Mobility & $2 / 73 \pm 0 / 64$ & $3 / 26 \pm 0 / 62$ & $3 / 29 \pm 0 / 52$ & $3 / 27 \pm 0 / 09$ & $\mathrm{~F}=0 / 865, \mathrm{P}=0 / 460$ \\
\hline Self-care & $3 / 50 \pm 0 / 17$ & $3 / 53 \pm 0 / 49$ & $3 / 66 \pm 0 / 36$ & $3 / 60 \pm 04$ & $\mathrm{~F}=0 / 986, \mathrm{P}=0 / 400$ \\
\hline $\begin{array}{c}\text { Household tasks and } \\
\text { family roles }\end{array}$ & $2 / 83 \pm / 14$ & $3 / 27 \pm 0 / 61$ & $3 / 27 \pm 0 / 52$ & $3 / 28 \pm 0 / 55$ & $\mathrm{~F}=0 / 035, \mathrm{P}=0 / 991$ \\
\hline Spending money & $2 / 83 \pm 0 / 58$ & $2 / 97 \pm 0 / 50$ & $3 / 20 \pm 0 / 49$ & $3 / 17 \pm 0 / 44$ & $\mathrm{~F}=3 / 740, \mathrm{P}=0 / 012$ \\
\hline Leisure & $2 / 83 \pm 0 / 76$ & $2 / 83 \pm 0 / 66$ & $2 / 81 \pm 0 / 44$ & $2 / 88 \pm 0 / 51$ & $\mathrm{~F}=0 / 189, \mathrm{P}=0 / 904$ \\
\hline Social relations & $3 / 96 \pm 0 / 26$ & $3 / 78 \pm 0 / 37$ & $3 / 93 \pm 0 / 41$ & $3 / 92 \pm 0 / 39$ & $\mathrm{~F}=2 / 657, \mathrm{P}=0 / 049$ \\
\hline $\begin{array}{c}\text { Paid and voluntary } \\
\text { work }\end{array}$ & $1 / 50 \pm 0 / 00$ & $1 / 55 \pm 0 / 71$ & $3 / 38 \pm 0 / 51$ & $3 / 04 \pm 0 / 42$ & $\mathrm{~F}=37 / 821, \mathrm{P}<0 / 001$ \\
\hline Education and learning & $1 / 50 \pm 0 / 00$ & $1 / 26 \pm 0 / 29$ & $1 / 77 \pm 0 / 71$ & $1 / 39 \pm 0 / 28$ & $\mathrm{~F}=12 / 961, \mathrm{P}<0 / 001$ \\
\hline $\begin{array}{c}\text { Assistance and support } \\
\text { of others }\end{array}$ & $4 / 53 \pm 0 / 50$ & $4 / 13 \pm 0 / 42$ & $4 / 17 \pm / 38$ & $4 / 19 \pm 0 / 36$ & $\mathrm{~F}=1 / 260, \mathrm{P}=0 / 289$ \\
\hline $\begin{array}{c}\text { Playing a role in } \\
\text { religious affairs }\end{array}$ & $3 / 18 \pm 0 / 54$ & $3 / 30 \pm 0 / 59$ & $3 / 11 \pm 0 / 61$ & $3 / 26 \pm 0 / 58$ & $\mathrm{~F}=1 / 329, \mathrm{P}=0 / 267$ \\
\hline
\end{tabular}




\section{Discussion}

Regarding the mean scores in the dimension of mobility, the rate of participation of the subjects in this dimension was 16.34 out of 23, and $46.3 \%$ of patients obtained a score of lower than average and $53.7 \%$ obtained a score of higher than average. In the dimension of self-care, the mean score was $21.64 \pm 2.60$ out of $28 ; 69.2 \%$ and $30.8 \%$ of subjects obtained a score lower and higher than the average score, respectively. No previous study was found on these two dimensions; however, in the study by Haririan, approximately $71.33 \%$ of patients with DM had dissatisfactory QOL in the physical dimension (18). It seems that the undesirability of this dimension in terms of the degree of participation is due to the complications of DM and the various physical issues experienced by individuals with DM. In the dimension of household tasks and family roles, the mean score obtained was $22.96 \pm 3.87$ out of 33 ; the score of $49.8 \%$ and $50.2 \%$ of the participants was, respectively, lower and higher than the average score. In the study of Ba Issa in Nigeria, $68.1 \%$ of patients had an average QOL in the physical aspect (19). This may be due to the similarity of the physical status of their participants to that of the participants in the present study.

The mean participation score in the dimension of spending money was $6.18 \pm 0.99$ out of 8 ; $70 \%$ and $30 \%$ of the participants, respectively, obtained a score lower and higher than the average score. No comparable study was found in this regard. The mean score of the dimension of leisure was $5.67 \pm 1.11$ out of 8 ; $43.2 \%$ of participants obtained a score lower than the average score and $56.8 \%$ of them obtained a score higher than the average score. The mean score of the dimension of social relations was $30.90 \pm 3.14$ out of $38 ; 70.9 \%$ of participants obtained a score lower than the average and $29.1 \%$ obtained a score higher than the average. The results of the study by Baghery et al. showed that patients with DM and vascular complications had lower QOL score in the social dimension compared to patients without vascular complications (12). It seems that their low score is due to their unsuitable relationship with their spouse, children, and other family members (12). When individuals with DM realize they are not the subject of the attention of others or that individuals or organizations and centers they depend upon do not support them, they desire isolation and loneliness and greatly reduce their social connections (18).

The mean score of the paid and voluntary work dimension was $16.62 \pm 6.19$ out of 28 ; $8.40 \%$ and $91.6 \%$ of patients, respectively, obtained a score lower and higher than the average. In the study by Baghiani-Moghadam et al., a significant relationship was observed between occupation and QOL of patients with DM (20). Timareh Mehnoosh also stated, in his study, that occupation is of great importance in the life of patients with DM, and thus, be taken into consideration (21).

Moreover, the mean score of the education and learning dimension was $2.97 \pm 1.08$ out of 8 ; $23.8 \%$ of the subjects obtained a score lower than average and $76.2 \%$ obtained a score higher than average. No similar and comparable studies were found in this regard. The patients' desire to learn and obtain information regarding their disease and also the educational requirement in this regard due to lack of knowledge on the disease and its management, diet therapy, pharmacotherapy, and etcetera may be the cause of this result. The mean score of the assistance and support of others was $5.56 \pm 1.11$ out of $8 ; 48.9 \%$ of patients obtained a score lower than average and $51.1 \%$ obtained a score higher than average. The mean score of playing a role in religious affairs was $20.80 \pm 1.98$ out of 25 ; $74 \%$ of patients obtained a score lower than average and $26 \%$ obtained a score higher than average. No similar studies were found on these dimensions; nevertheless, the physical and mental complications of DM and the patients' poor social relations may be effective 
in this regard. In the present study, the highest participation score was related to the 30-49 year age group. Sadeghi et al. also found that the QOL of patients with DM has an inverse relationship with their age (22). This finding was in agreement with that of the present study. Senes et al. also found that with increase in age, the QOL of patients with DM decreased (23). This reduction in QOL may be due to increased physical and emotional limitations and limitations in self-care or increased cardiovascular, neurovascular, and neuropathy symptoms, and other complications of diabetes due to increased age. This study also showed that the participation rate of men in the dimensions of spending money, social relations, and paid and voluntary work was higher. Senez et al. also reported that QOL of women with DM was lower compared to men with DM (23). They attributed this to physical and mental issues caused by menopause and their economic dependence (23). In the present study, the participation of single individuals in the dimensions of spending money and social relations was higher compared to married individuals. In the study by Saadatjou et al., the QOL of single individuals was higher than married individuals (24). They reported significant differences between the QOL scores of single and married individuals in the majority of QOL dimensions (24). This finding is in agreement with that of the present study. The greater participation of single individuals may be due to their better controlling of the disease and its complications due to fewer preoccupations and responsibilities, and thus, more time for treatment and care follow-up. The results also showed that participation in the dimensions of spending money, paid and voluntary work, and education and learning is higher in patients with a good economic status. The findings of the study by Haririan also showed that economic factors can impact the QOL of patients with DM and cause changes in different dimensions of QOL (18). The study by $\mathrm{Ba}$ Issa also showed that poor QOL of patients with DM was correlated with low monthly income (19). The findings of both studies are in accordance with that of the present study. It can be concluded that personal, social, and economic factors have an important role in the degree of participation of patients with DM in their life affairs and must be considered in the assessment of these patients. Furthermore, the care measures and treatment interventions performed in these patients must be dedicated to the improvement of their participation and QOL. In addition, the increasing of their participation in life affairs and QOL must be assisted through the use of support centers for patients with DM and provision of educational and consultation services with the aim to increase social support and reduce the complications of DM. The present study and previous studies in Iran and other countries showed that the incidence of $\mathrm{DM}$ is the beginning of the reduction in participation and QOL. With the consideration of the long-term course of the disease, taking measures to improve participation and QOL seems necessary. The first step in this direction is the determination of patients' most important life aspects affected by DM. The present study showed that planning to improve the status of the dimensions of participation is necessary in all dimensions and fields related to patients' participation in their life. Similar studies in other populations and areas of the country will provide a clear image of the participation of patients with DM and their results will assist in plans for the provision of treatment services for this growing group in the country.

The most important limitation of the present study was the lack of participation of patients with type II diabetes in the study.

\section{Conclusion}

The results of the present study suggested the presence of a significant relationship between the participation of patients with type II DM and their age, gender, marital status, disease severity, and social and economic status. 
Furthermore, the data obtained from the IPA-p scale showed that the level of participation of these patients in most dimensions was lower than the mean scores of participation.

\section{Acknowledgements}

The authors wish to thank all their colleagues at and personnel of the diabetes clinic of Aliibn Abi Talib Hospital affiliated to Rafsanjan University of Medical Sciences for their cooperation in data collection, and all patients who participated in this study.

Conflict of interest: None declared

\section{References}

1- Badely EM, Thompson RP, Wood PH. The prevalence and severity of major disabiling conditions-- a reappraisal of the government social survey on the handicapped and impaired in Great Britain. Int J Epidemiol 1978; 7(2):145-51.

2- Myrray CJ, Lopez AD. Regional patterns of disability-free life expectancy and disabilityadjusted life expectancy: global burden of disease study. Lancet 1997; 349(9062):134752.

3- Barer D, Nouri F. Measurment of activities of daily living. Clinical Rehabilitation 1989; 3(3):179-87.

4- Skerington S, Mac Arthur P, Sumerset M. Developing item for the WHO QOL: An investigation of contemporary beliefs about quality of life related to health in Britain. $\mathrm{Br} \mathrm{J}$ Health Psychol 1997; 2(1):55-72.

5- World Health Organization. Draft; Programme on mental health. WHOQOL User Manual. Division of Mental Health and Prevention of Substance Abuse. Switzerland, Geneve: World Health Organization; 1998. Report No.:WHO/MNH/MHP/98.4.Rev.1 Available from:

6- Solari A, Filippini G, Mendozzi L, Ghezzi A, Cifani S, Barbieri E, et al. Validation of Italian multipe sclerosis quality of life 54 questionnaire. J Neurol Neurosurg Psychiatry 1999; 67(2):158-62.

7- Murrell RC, Kenealy PM, Graham Beaumont J, Lintern TC. Assessing quality of life in persons with severe neurological disability associated with multiple sclerosis: the psychometric evaluation of two quality of life measures. Br J Health Psychol 1999; 4(4):34962.

8- Vazirinejad R. A commiunity-based survey of quality of life and participation among people with multiple sclerosis [PhD thesis]. Nattingham: University of Nattingham; 2003.

9- Cardol M, de Haan RJ, van den Bos GA, de Jong BA, de Groot IJ. The development of a handicap assessment questionnaire: the impact on participation and autonomy (IPA). Clin Rehabil 1999; 13(5):411-9.

10- World Health Organization. ICIDH-2: Internatinal of classification of functioning and disability, Beta-2 Draft. Assessment, Classification and Epidemiology Group. Switzerland, Geneve: World Health Organization; $1999 . \quad$ Report No.:WHO/HSC/ACE/99.1.

11- DarvishPoor kakhki A, Abed Saeedi Z, Yaghmaie F, Alavi Majd H, Montazeri A. Survey correlation between quality of life and disease and demographic variables of diabetic patients referred to Tehran hospitals in 2004. Iranian Journal of Endocrinology and Metabolism 2006; 8(1):49-56.

12- Bagheri H, Ebrahimi H, Taghavi N, Hassani MR. Evaluation of quality of life in patients with diabetes mellitus, based on its complications, referred to Imam Hossein Hospital, Shahrood. Journal of Shahrekord University of Medical Sciences 2005; 7(2):506.

13- Aguiree F, Brown A, Cho NH, Dahlquist G, Dodd Sh, Dunning T, et al. IDF Diabetes Atlas. $6^{\text {th }}$ ed. Basel, Switzerland: International Diabetes Federation; 2013.

14- American Diabetes Association. Classification and diagnosis of diabetes. Diabetes Care 2016; 39 (Supplement 1):S13-22.

15- EI Achhab Y, Nejjari C, Chikri M, Lyoussi B. Disease-specific health related quality of life instruments among adults diabetic: a systematic review. Diabetes Res Clin Pract 2008; 80(2):171-84.

16- Kerten P, Sibley A, Ward CD, White B, George SL. The validity and reliability of the impact on participation and autonomy questionnaire. Clinical Rehabil 2005; 19(5):572-8.

17- Vazirinejad R, Joorian J, Taghavi MM, Lilley JM, Sayadi Anari AR. The persian version of a participation scale; Is it valid and reliable enough for use among Iranian patient with multiple sclerosis? J Clin Neurol 2015; 11(2):157-63.

18- Harririan H, Moghadasian S, Aghajanloo A. Quality of life and its dimensions in diabetic patients referred to the Diabete Center of 
Tabriz University of Medical Sciences in 2008. Iranian Journal of Diabetes \& Metabolism 2008; 9(2):152-60.

19- Issa BA, Baiyewu O. Quality of life of patient with diabetes mellitus in a Nigerian teaching hospital. Hong Kong Journal of Psychiatric 2000; 16(1):27-33.

20 Baghianimoghadam MH, Afkhami Ardakani M, Mazloomi SS, Saeedzadeh M. Quality of life in diabetes type II patients in Yazd. Journal of Shahid Sadoughi University of Medical Sciences and Health Services 2007; 14(4):4954.

21- Timareh M, Rahimi M, Abbasi P, Rezaei M, Hyadarpoor S. Quality of life in diabetic patients referred to the diabete research center in Kermanshah. Journal of Kermanshah University of Medical Sciences 2012; 16(1):63-9.

22- Sadeghi Ahari $S$, Arshi S, Iranparvar $M$, Amani F, Siahpoosh H. The effect of complictions of typeII diabetes on patientes quality of life. Journal of Ardabil University of Medical Sciences 2009; 8(4):394-402.

23- Senez B, Felicioli P, Moreau A, Le Goaziou MF. Quality of life assessment of type 2 diabetic patientes in general medicine. Presse Med 2004; 33(3):161-6.

24- Saadatjoo SA, Rezvanee MR, Tabyee Sh, Oudi D. Life quality comparison in type 2 diabetic patientes and none diabrtic persons. Modern Care Journal 2012; 9(1):24-31. 